\title{
Contribuciones del protocolo a la creación de las autoridades en España.
}

\author{
How protocol contributes to create the public image of the \\ authorities in Spain.
}

\author{
Carmen Cuadrado Esclapez \\ Universidad Complutense de Madrid \\ carmecua@ucm.es
}

Recepción: 30/04/2018 Revisión: 03/06/2018 Aceptación: 05/06/2018 Publicación: 30/06/2018

\begin{abstract}
Resumen
La creación y transmisión de una determinada imagen mediática en coherencia con unos objetivos previamente definidos requiere un plan de comunicación estratégico, del cual el protocolo es parte fundamental. El propósito de este trabajo es comprobar cómo los criterios protocolarios de jerarquía espacial y escenografía simbólica afectan a la imagen de una autoridad. Este estudio concluye que el actor político comunica control, dominio, autoridad y poder mediante la observancia de las normas protocolarias. Sin embargo, se ha comprobado que el protocolo deja sin cobertura aspectos primordiales del control estratégico de la imagen pública. Resulta, pues, insuficiente si no se complementa con otros canales no verbales que transmiten atributos asociados al carisma.
\end{abstract}

Palabras claves: Protocolo, comunicación, imagen, poder, carisma

\section{Abstract}

The creation and conveyance of a specific media image related to previously defined objectives require a strategic communication plan, of which Protocol is a fundamental part. This research contributes to demonstrate how the protocol criteria of space, hierarchy and symbolic scenery affect a leader's image. It is concluded that the leader conveys control, dominance, authority and power through the respect of the protocol rules. However, protocol does not take into account many remarkable aspects of the strategic control of the politician's image. Subsequently, this research proposes that it should be complemented with channels of the non-verbal language in charge of conveying the qualities linked to charisma. 
Keywords: Protocol, communication, image, power, charisma

\section{Sumario}

\section{Introducción}

2. Desarrollo

3. Recolección de datos

4. Discusión

5. Conclusiones

6. Bibliografía y Webgrafía

\section{INTRODUCCIÓN}

El propósito de este artículo es demostrar cómo el protocolo, elemento decisivo para alcanzar los objetivos comunicacionales de los objetos sobre los que opera -los actos públicos-, contribuye a la construcción de la imagen pública del sujeto protagonista de esos actos. La creación y transmisión de una determinada imagen mediática en coherencia con unos objetivos previamente definidos requiere un plan de comunicación estratégico, del cual el protocolo es parte fundamental. El protocolo supone, además, una importante fuente de información para interpretar las actuaciones de los políticos en los actos públicos en los que intervienen.

Mediante este estudio hemos comprobado cómo los criterios protocolarios de ordenación espacial y escenografía simbólica afectan a la imagen de una autoridad, e influyen en la transmisión de credibilidad, autoridad y poder. Hemos incluido una tercera variable: las señales de dominio y liderazgo que emiten los sujetos a través del contacto táctil o háptica ${ }^{1}$. Se trata de un aspecto englobado dentro de una de las disciplinas integradas en la comunicación no verbal que complementan al protocolo y resultan indispensables para el control estratégico de la imagen de un líder. Se pretende demostrar que el especialista en protocolo necesita dominar múltiples materias si quiere llevar a cabo un control íntegro de la imagen mediática del actor político.

Se han aplicado estas variables al acto de bienvenida en el que el presidente del Gobierno recibe a los distintos presidentes de Consejo de Gobierno autonómico a las puertas del Palacio de La Moncloa en el marco de las audiencias que se les concede.

En este acto hay una marcada escenografía y un protocolo basado en la costumbre, pues no se trata en sentido estricto de un acto público oficial ${ }^{2}$, sino de un encuentro formal

1 Toledo, C., Háptica, el poder del tacto como canal de comunicación no verbal en la política. http://www.analisisnoverbal.com/haptica-en-comunicacion-no-verbal-politica/

2 Los actos públicos oficiales de carácter general son los efectuados con ocasión de acontecimientos nacionales, autonómicos o locales. Los actos públicos oficiales de carácter especial son los organizados por determinadas instituciones, organismos y autoridades para conmemorar acontecimientos propios de su ámbito 
que el presidente prevé en su agenda (por ejemplo, tras la convocatoria de elecciones autonómicas, el jefe del Ejecutivo recibe a los recién nombrados jefes de Consejo de Gobierno de las Comunidades Autónomas); aunque bien es cierto que, en el ámbito protocolario, la costumbre ${ }^{3}$ suele estar fundamentada en el reglamento de los actos públicos oficiales. En este caso, el reglamento en el que se basa la costumbre establecida es el siguiente:

- Ordenación General de Precedencias del Estado. Real Decreto 2099/83 de 4 de agosto..

- Ley 39/81 de 28 de octubre, sobre la Bandera Nacional (BOE 271 de 12 de noviembre). Norma reguladora de los símbolos del Estado.

Se ha seleccionado como sujeto de estudio principal al actual presidente del Gobierno español, Mariano Rajoy, por tratarse del máximo representante del poder Ejecutivo, y a los presidentes de los Consejos de Gobierno de las Comunidades Autónomas, como sujetos secundarios. Desde el punto de vista protocolario, estimamos que la cualidad de estos - primeras autoridades - puede aportar información concluyente y valiosa.

La recolección de datos se obtiene del material audiovisual (vídeos y fotografías) publicado en la página web de La Moncloa, en concreto, de su sección Multimedia durante el período que comprende del 27 de enero de 2012 (fecha del comienzo de la legislatura) hasta el 2 de septiembre de 2015, que incluye un total de treinta audiencias.

\section{DESARROLLO}

\subsection{Revisión de antecedentes y contexto del caso}

Del año 2004, con José Luis Rodríguez Zapatero al frente del Gobierno, datan las primeras imágenes en las que apreciamos un marcado protocolo en la recepción de los presidentes de Consejo de Gobierno de las Comunidades Autónomas.

Pasamos a describir el protocolo de bienvenida: el presidente autonómico es recibido por el jefe del Ejecutivo en la puerta principal de acceso al Palacio de La Moncloa, situada en la fachada noroeste del edificio. El anfitrión espera en lo alto de la escalinata la llegada del coche oficial. A su llegada, la visita desciende del coche y se dirige a la entrada.

específico, que igualmente se enmarcarán dentro de una determinada territorialidad. FUENTE LAFUENTE, C., Protocolo Oficial. Las instituciones españolas del Estado y su ceremonial. Madrid, Ediciones Protocolo, 2010.

3 Es importante resaltar el ámbito de aplicación de la ley, pues cuando las autoridades concurren a actos de carácter no oficial, el anfitrión no tiene la obligación de ceñirse al presente Ordenamiento para establecer las prevalencias. Aunque es cierto que se suele respetar, por cortesía, las pautas de ordenación del Real Decreto. Fuente Lafuente, C., Protocolo Oficial. Las instituciones españolas del Estado y su ceremonial. Madrid, Ediciones Protocolo, 2004, p. 83. 
Fachada noroeste del palacio de La Moncloa

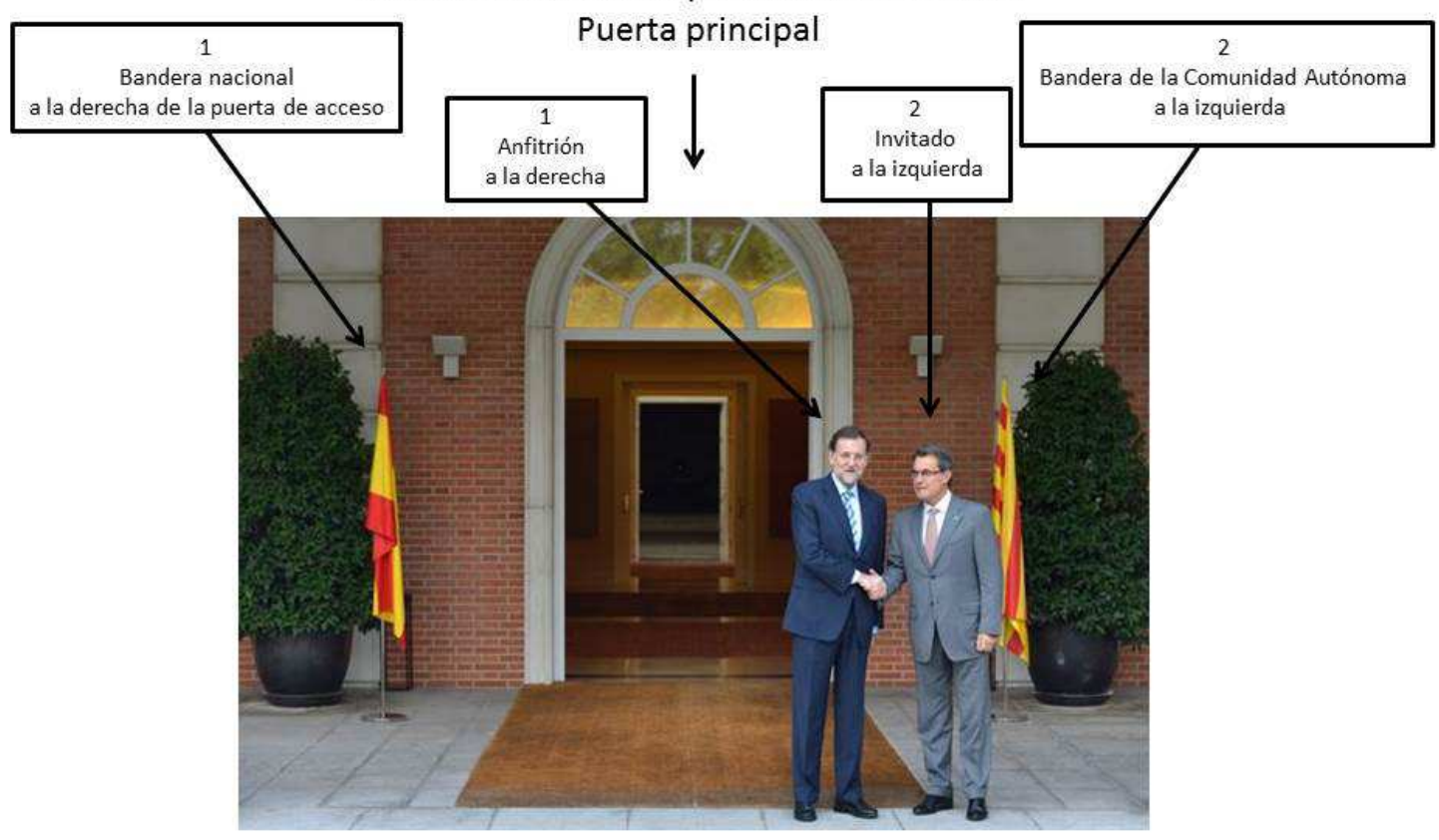

Figura 1.

Elaboración propia. Fuente:

lamoncloa.gob.es/multimedia/galeriasfotograficas/Presidente/Paginas/2012/200912_Rajoy

_Mas4.aspx

Consultado el 4-07-2016

Durante el saludo, el anfitrión se ubica a la derecha ${ }^{4}$ de su invitado para respetar la "ley de la derecha protocolar", la cual determina que, desde el punto de vista espacial, la derecha es más importante que la izquierda, ya que se considera el lugar de honor ${ }^{5}$. En el artículo 10 del Ordenamiento General de Precedencias del Estado, establecido en el Real Decreto 2099/83 de 4 de agosto, que ordena las precedencias de las autoridades en los actos de carácter oficial organizados por la Corona, el Gobierno o la Administración del Estado, el presidente del Gobierno español ocupa el puesto número 5, mientras que a los presidentes de los Consejos de Gobierno autonómico se les asigna el 14. En este caso encontramos, pues, coherencia entre lo que determina la ley y lo que aplica la costumbre. La figura 1 es un ejemplo de lo que se acaba de exponer.

4 Cuando nos referimos a la "derecha" siempre tomamos como referencia a la persona que preside, o la presidencia física, (un altar, por ejemplo) que corresponde a la izquierda del observador. López-Nieto Y Mallo, F., Manual de protocolo (2a Ed.) Barcelona, Editorial Ariel, S.A., 1997.

5 Sin embargo, el visitante fuera un homólogo de otro país o un jefe de Estado extranjero, el presidente del Gobierno español -por cortesía, en el caso del primero, y por criterios jerárquicos, en el caso del segundo- los situaría a su derecha. El criterio de cesión de la derecha tiene aplicación internacional. Cuadrado Esclapez, C., Protocolo y comunicación en la empresa y los negocios. Madrid, Editorial Fundación Confemetal, 2000 
Para establecer cuál es la derecha se toma como referencia la fachada del acceso principal. Rajoy se encuentra la derecha de su invitado. Sin embargo, desde la perspectiva del observador de la imagen, el lugar que ocupa el presidente del Gobierno se corresponde con la izquierda. Ambos se sitúan de cara a la prensa.

En este acto de bienvenida, el saludo supone el momento culmen del encuentro, pues se trata de la instantánea más codiciada desde el punto de vista mediático. El saludo, como elemento de comunicación no verbal, es un gesto revelador del estado de salud de las relaciones entre mandatarios. La prensa suele destacar la forma en que se produce. Por ejemplo, al referirse a uno de los encuentros entre Mariano Rajoy y Artur Mas, el periódico digital El Mundo.es comenta (artículo 1): "Los dos dirigentes han protagonizado un frío saludo al inicio de la cita [...] Casi sin mirarse a la cara se han saludado una segunda vez, a petición de los reporteros".

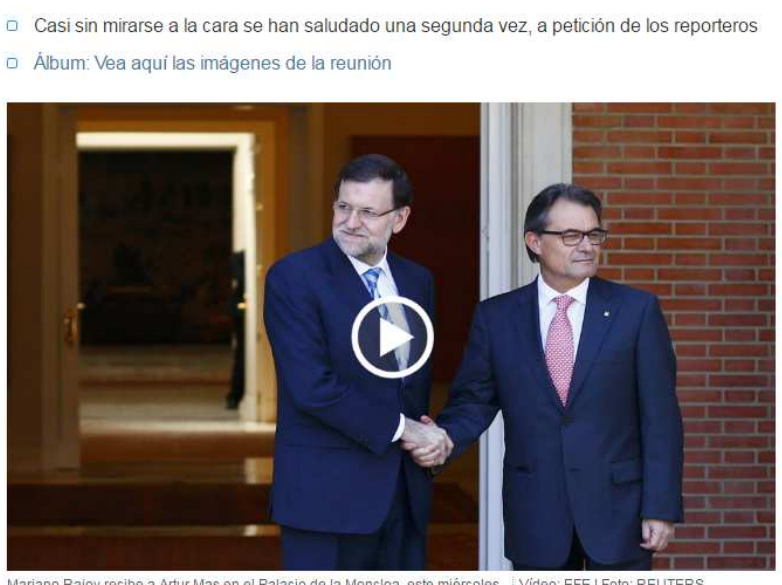

Artículo 1.

Fuente: elmundo.es/espana/2014/07/30/53d7e583ca4741ab528b4594.html

Consultado el 4-07-2016

\subsection{Escenografía del acto}

El escenario de recepción es el siguiente: las dos banderas, nacional y autonómica, se sitúan a ambos lados de la puerta principal del edificio. A la derecha -siguiendo el criterio de la derecha protocolar- se coloca la bandera nacional y a la izquierda se dispone la bandera de la Comunidad Autónoma invitada.

De la costumbre de dicha escenografía se tiene constancia a partir del año $2004^{6}$. Es de destacar que no se han encontrado fotografías de la recepción de los presidentes de Comunidades Autónomas a las puertas del Palacio de La Moncloa durante la legislatura de

6 De este año datan las primeras imágenes que hemos encontrado donde se reconoce el establecimiento de un protocolo para estos encuentros. 
los anteriores presidentes de Gobierno. En los archivos consultados ${ }^{7}$ solamente queda constancia gráfica de estas audiencias en el interior del Palacio.

No obstante, sí se han hallado imágenes a las puertas del Palacio de La Moncloa de los encuentros entre Aznar y mandatarios de otros países. Comprobamos, además, que se aplica el criterio de cortesía, el cual establece que, en los encuentros bilaterales, el anfitrión ceda la derecha a su invitado siempre y cuando este sea su homólogo o goce de un rango superior. Veamos un ejemplo:

José María Aznar ejerce la cortesía con su invitado, el presidente de Estados Unidos, y le cede su derecha (fotografía 1). En realidad, esta le corresponda a Aznar por su condición de anfitrión. Por esta razón empleamos el término "cesión".

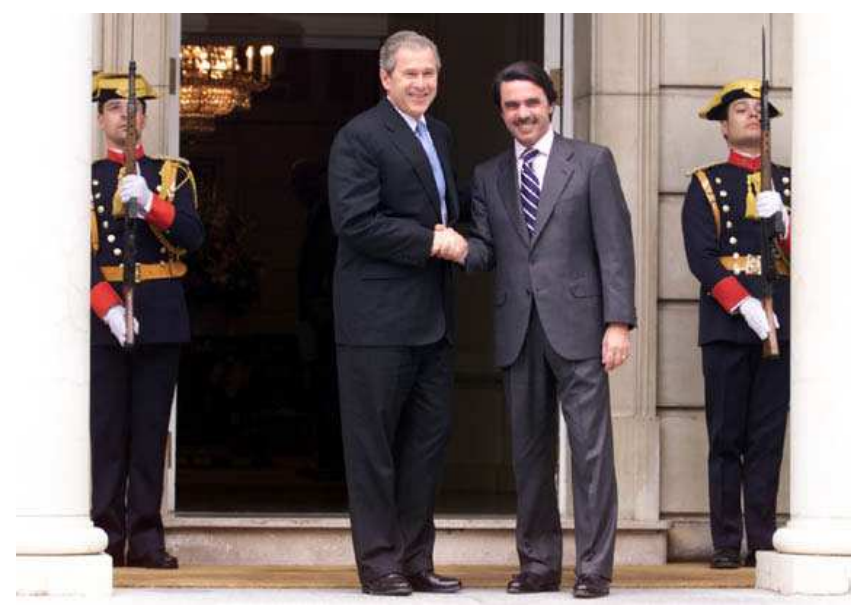

\section{Fotografía 1.}

13-06-2001. Palacio de La Moncloa. Aznar recibe al presidente de Estados Unidos. Fuente: http://es.wikipedia.org/wiki/Jos\%C3\%A9_Mar\%C3\%ADa_Aznar Consultado el 10-07-2016

Si retomamos la legislatura de José Luis Rodríguez Zapatero, en el año 2010 el equipo de Gobierno crea la página web de La Moncloa, con una sección multimedia que incluye una galería fotográfica donde se publican las fotografías de las actividades del Ejecutivo. El cuidado de la imagen de los actos y los encuentros en los que participa el presidente durante su último año de gobierno es notorio ${ }^{8}$. Por otra parte, al comienzo de su mandato, Rodríguez Zapatero realiza modificaciones sustanciales en el escenario de las audiencias concedidas a los presidentes autonómicos en el interior del Palacio de La Moncloa. Por ejemplo, incluye en la escenografía las banderas nacional y autonómica. Veamos, en primer lugar, la puesta en escena de estos encuentros y la ambientación del

7 Archivo gráfico de Carta de España (Ministerio de Empleo y Seguridad Social) y archivos de agencia EFE y periódicos El Mundo y El País.

8 La Moncloa. Home <http://www.lamoncloa.gob.es/Paginas/index.aspx> 
despacho presidencial durante los gobiernos de Felipe González (fotografía 2) y José María Aznar (fotografía 3):

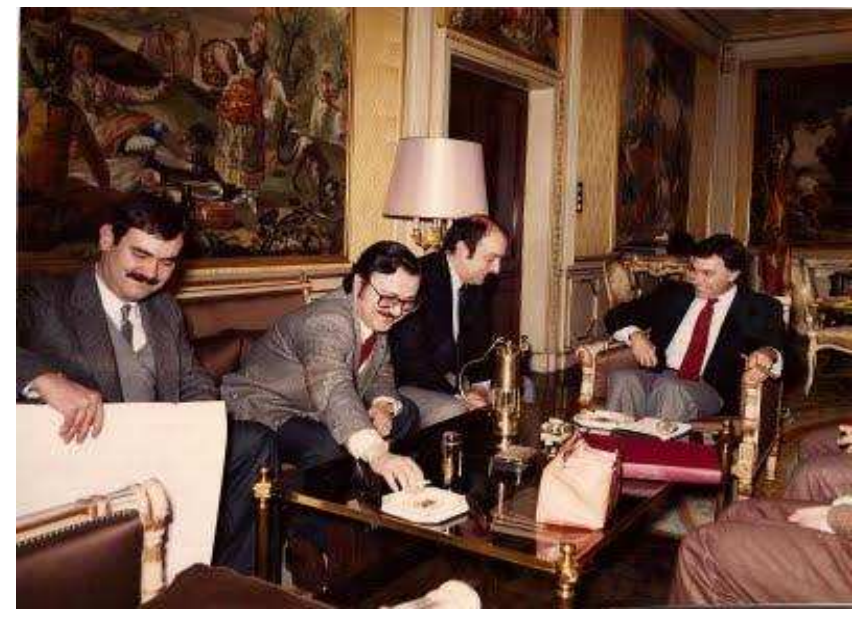

Fotografía 2.

Felipe González reunido en su despacho con varios interlocutores.

Fuente: http://es.paperblog.com/interiorismo-y-politica-5-Presidentes-del-gobierno-deespana-y-un-mismo-despacho-palacio-de-la-moncloa-madrid-espana-1977-2011-661454 Consultado el 10-07-2016

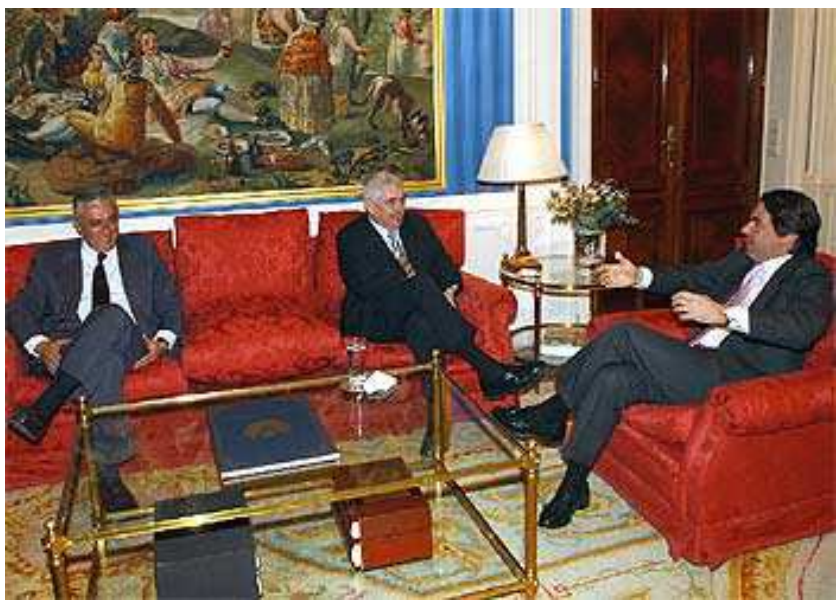

Fotografía 3.

Enero de 2004. José María Aznar recibe al nuevo presidente de la Generalidad catalana, Pasqual Maragall. Fuente: elpais.com/elpais/2004/01/08/actualidad/1073553422_850215.html

Consultado el 10-07-2016

Observamos en la fotografía 4 que se otorga un mayor protagonismo y visibilidad a los símbolos del Estado y se incluye la pluralidad de enseñas. 


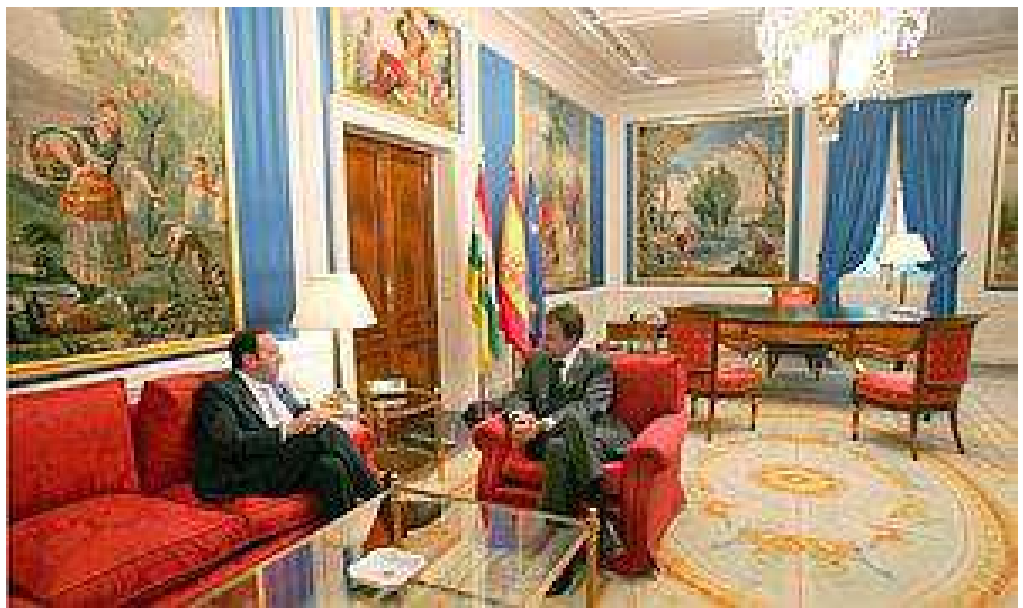

Fotografía 4.

Fuente: elcomercio.es/noticias/201111/20/Media/M1-1807156471--300x180.JPG

Consultado el 10-07-2016

La escenografía del protocolo de recepción de presidentes autonómicos se define, pues, durante el gobierno de Zapatero. Las modificaciones están orientadas a la transmisión de una imagen de modernidad y cambio. Se producen transformaciones notables en la decoración del despacho del presidente. El mobiliario de corte clásico y la decoración recargada se sustituyen por muebles de diseño minimalista y funcional con prevalencia del monocromatismo, con tonos neutros dentro de la gama del blanco y del gris. Se prescinde de tapices y alfombras, que aportan un aire barroco al ambiente, y el suelo se cubre con moqueta. La fotografía 5 refleja el afán de modernización, en consonancia con la imagen de cambio que pretende transmitir el Gobierno socialista.

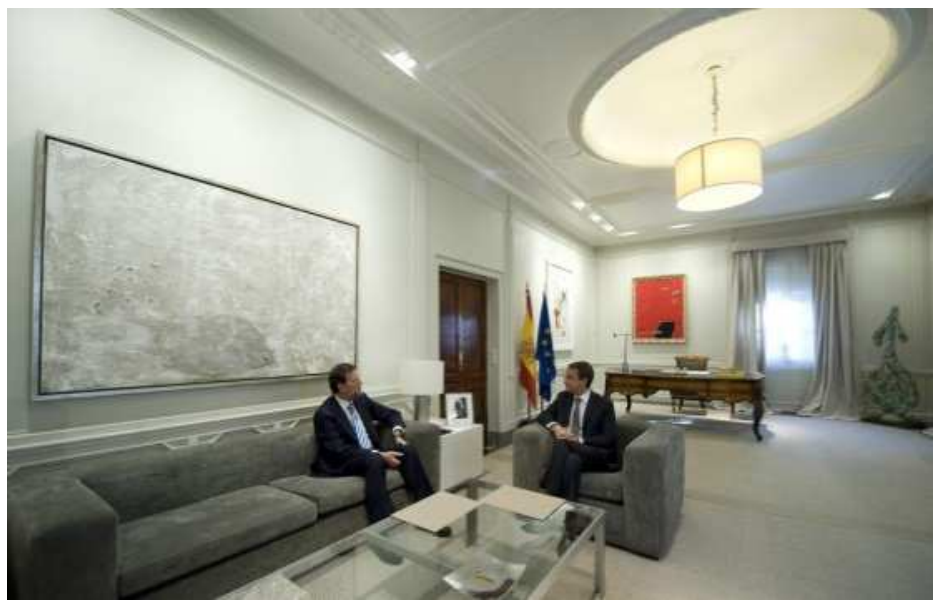

Fotografía 5.

El presidente Rodríguez Zapatero durante una reunión en su despacho.

Fuente: albertmedran.com/bloc_cast/wp-content/uploads/2016/04/despoficialzp.jpg Consultado el 10-07-2016

A continuación, mostramos la primera imagen de la audiencia con un presidente autonómico que inaugura la fototeca de web de La Moncloa (Fotografía 6): 


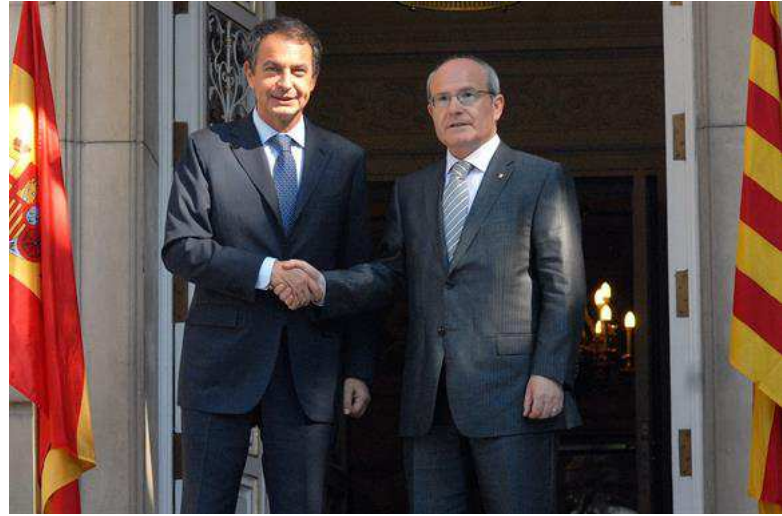

Fotografía 6.

21- 07-2010. Palacio de La Moncloa. El presidente Zapatero recibe a José Montilla, presidente de la Generalidad catalana.

Fuente:lamoncloa.gob.es/multimedia/galeriasfotograficas/Presidente/Paginas/2010/210720 10VisitaMontilla.aspx . Consultado el 10-07-2016

El presidente del Gobierno se ubica a la derecha de los presidentes de las Comunidades Autónomas. Comprobamos, pues, que el uso que se hace del espacio no es indiscriminado. A cada cual le corresponde un lugar que se asigna atendiendo a criterios de jerarquía cuando el rango es inferior y de cortesía cuando el encuentro es entre homólogos. Concluimos, por lo tanto, que hay diferencias significativas entre la escenografía de la recepción del presidente de una Comunidad Autónoma española y la recepción de un jefe de Estado o de un presidente de Gobierno de un país extranjero, y los honores que se rinden a cada uno. La figura 2 recoge estas diferencias:

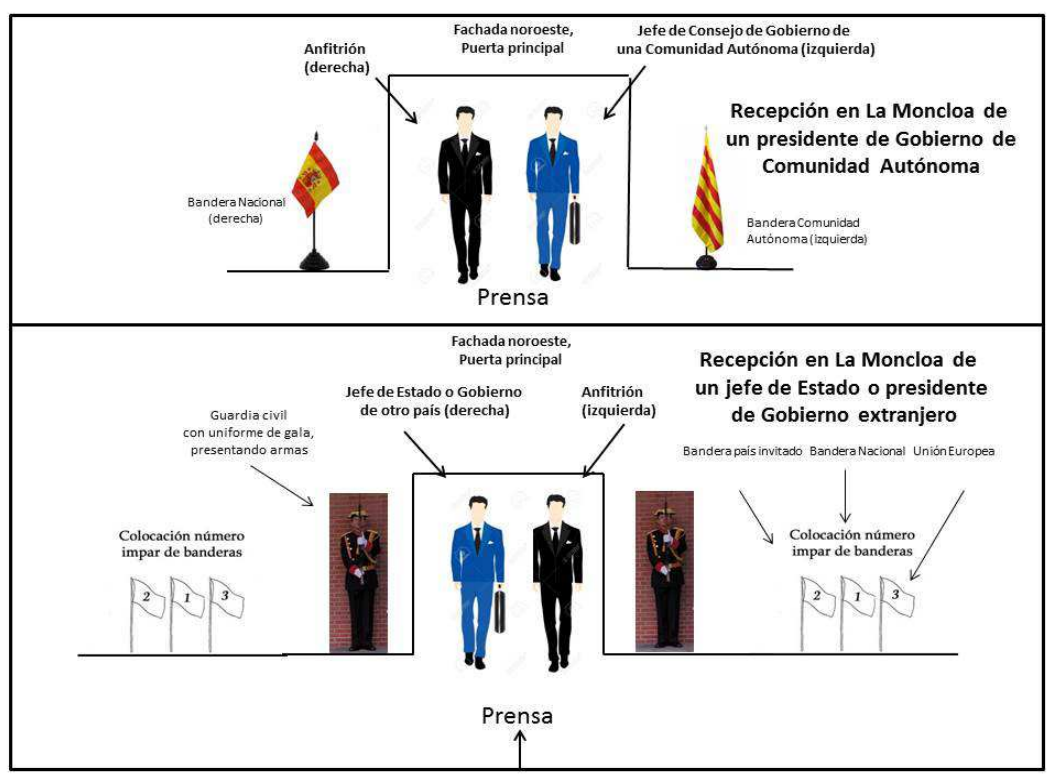

Figura 2. Elaboración propia 


\subsection{Simbología}

Por lo que respecta a la posición de las banderas en la puerta de entrada al Palacio de La Moncloa, el criterio de colocación es el que detallamos: la bandera de España se ubica a la derecha de la puerta principal y la bandera de la Comunidad Autónoma a la izquierda de esta, como establece la Ley 39/81, de 28 de octubre, que regula el uso de la bandera de España y que determina que debe ondear obligatoriamente en el exterior y ocupar un lugar preferente en el interior de los edificios y establecimientos de la Administración central, institucional, autonómica, provincial o insular y municipal del Estado. Se ubicará en el centro, lugar de honor, si el número de banderas es impar, y a la derecha, en el caso de que este sea par.

Hemos de aclarar que, aunque el uso de la bandera está regulado por ley, se refiere al tratamiento que se le ha de dar en cuanto a la obligatoriedad de ondear en los edificios oficiales y su prelación en relación con otras enseñas, pero no hace mención al número de banderas que ha de disponerse en situaciones como la que estamos analizando. En consecuencia, la disposición de una sola bandera -la nacional- a la derecha de la puerta de acceso al palacio y una única bandera -la autonómica- a la izquierda de la misma es una simple costumbre, que, como toda opción, admite otras. Por esta razón atribuimos al Gobierno de Zapatero esta plasmación del protocolo en cuanto al uso de los símbolos nacionales, dado que las primeras imágenes en las que se tiene constancia de esta escenografía corresponden a su mandato.

Durante las legislaturas de los distintos presidentes del Gobierno español a lo largo de la historia de nuestra democracia observamos que en las audiencias con los presidentes autonómicos se prescinde de sus enseñas en el interior de los despachos. No es hasta la legislatura de José Luis Rodríguez Zapatero cuando estas banderas adquieren relevancia en el escenario de los actos o encuentros convocados por el Ejecutivo. No parece haber habido hasta entonces una particular preocupación por que las enseñas tengan visibilidad o protagonismo en estos encuentros, ni tan siquiera la bandera de España, pues se le otorgaba una ubicación en la que difícilmente podía ser captada por los objetivos de los fotógrafos. Quizá la coyuntura socio-política del momento, en la que la unidad nacional no era objeto de debate y la pluralidad territorial española estaba en ciernes, no exigía la presencia visual de los emblemas patrios. Además, la mayoría de los Estatutos de Autonomía fueron aprobados entre los años 1982 y 1983. Por ejemplo, el presidente Aznar mantenía la bandera nacional al fondo de su despacho, pero no la incorporaba al escenario del encuentro. Se trataba de un elemento fijo dentro de la decoración de la estancia, que ejercía la función de símbolo del Estado. En la figura 3 constatamos la ausencia de la enseña autonómica. La bandera nacional aparece en un segundo plano, junto a la mesa de trabajo de José María Aznar. 


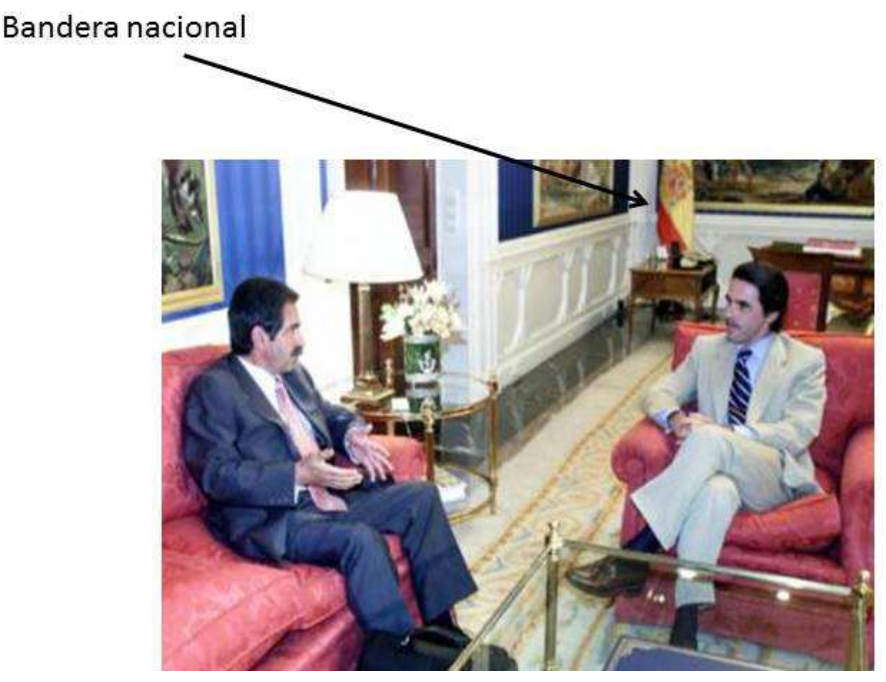

Figura 3. Elaboración propia.

Año 2004. El presidente Aznar recibe al presidente de Cantabria en La Moncloa.

Fuente de la fotografía: elheraldomontanes.wordpress.com/2015/07/07/miguel-angelrevilla-lo-que-sea-para-estar-en-la-poltrona

Consultado el 2-08-2016 en Internet

El primero que otorga protagonismo visual a los emblemas en las reuniones con los presidentes autonómicos es José Luis Rodríguez Zapatero (fotografía 7). Comprobamos en la figura 4 que la bandera de España se desplaza desde el fondo del salón hasta la puerta de acceso a la estancia con objeto de que pueda ser captada por las cámaras de los periodistas. Junto a ella, se incorporan la bandera autonómica y la enseña de la Unión Europea (que, posteriormente, será eliminada de este tipo de audiencias).

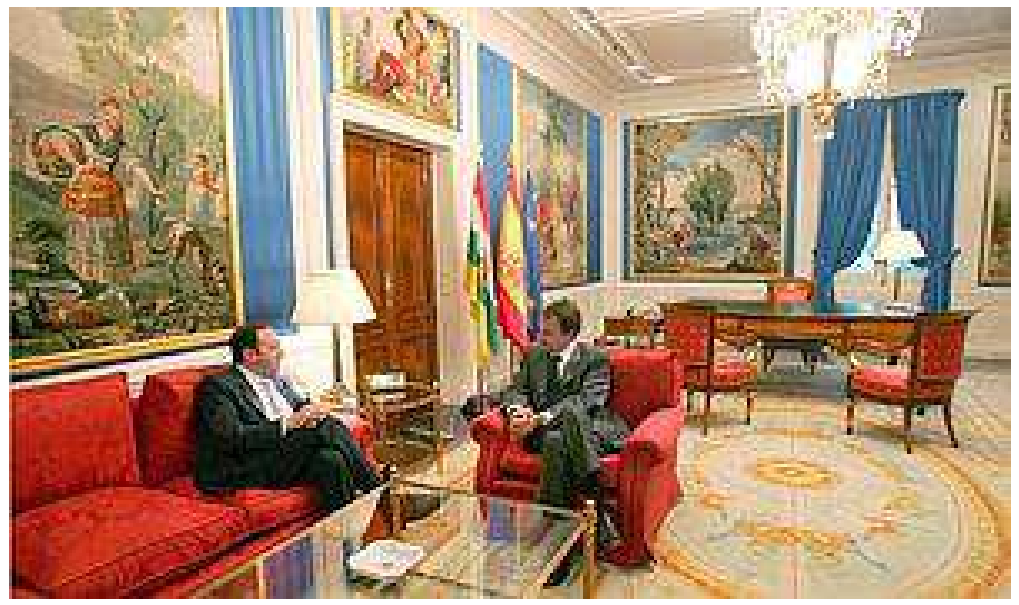

Fotografía 7.

Encuentro de Rodríguez Zapatero con el presidente de la Rioja en el Palacio de La Moncloa. Fuente: elcomercio.es/20111120/mas-actualidad/sociedad/moncloa- 201111200909.html

Consultado el 2-08-2016 en Internet 
2

1

Bandera de la Comunidad Autónoma

Bandera nacional 3

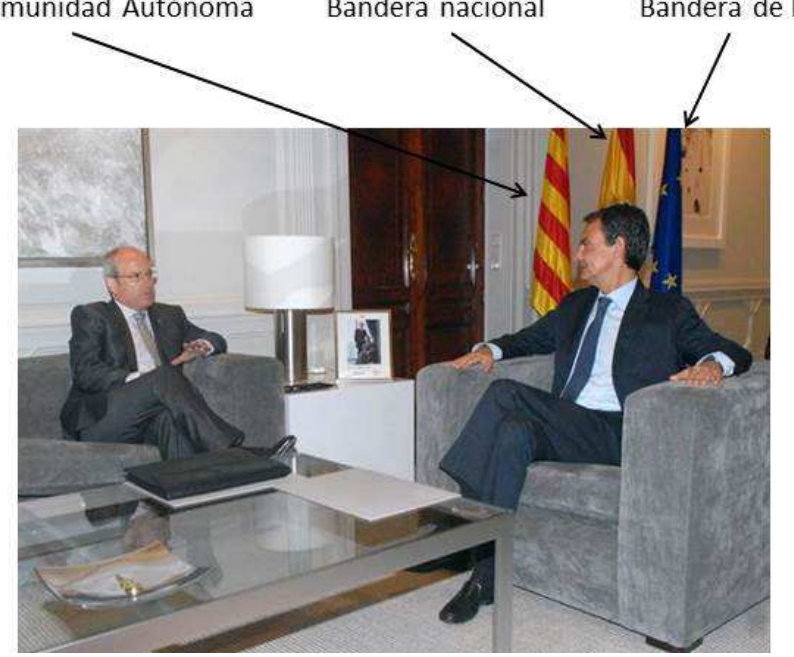

Figura 4. Elaboración propia.

Encuentro de Rodríguez Zapatero con el presidente de la Generalidad catalana José

Montilla.Fuente:

lamoncloa.gob.es/multimedia/galeriasfotograficas/Presidente/Paginas/2010/21072010Visit aMontilla.aspx

Consultado el 2-08-2016 en Internet

\section{RECOLECCIÓN DE DATOS}

\subsection{Resultados del análisis de los criterios protocolarios de ordenación espacial y escenografía simbólica}

De las treinta audiencias analizadas, el presidente del Gobierno, Mariano Rajoy, se ubica a la izquierda de su interlocutor en siete ocasiones. Este hecho supone la pérdida de la condición de anfitrión desde el punto de vista espacial -protocolario- pues Rajoy ocupa el lugar que se adjudica al invitado.

Los errores son más frecuentes durante las quince primeras recepciones; la proporción es de $15 / 1$ y de $15 / 6$.

A lo largo de estas treinta recepciones, el gabinete de Protocolo ha estado utilizando dos escenarios simbólicos: en veintitrés ha dispuesto dos banderas, la nacional y la autonómica, y en siete ha añadido a estas la enseña de la Unión Europea.

En la audiencia número quince, correspondiente a la segunda audiencia que se le concede a Artur Mas el 20 de septiembre de 2012, el presidente catalán sube la escalinata que le conduce hasta la puerta del Palacio de La Moncloa por el lado izquierdo de la fachada y se detiene junto a su enseña autonómica, de manera que ambas autoridades posan únicamente ante la bandera catalana. 


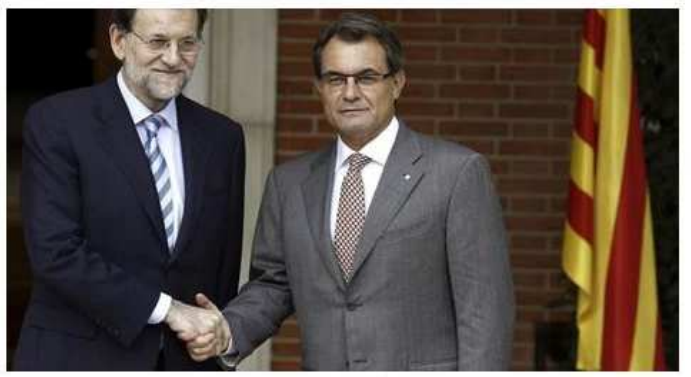

Fotografía 1

El Mundo. 20-09-2012

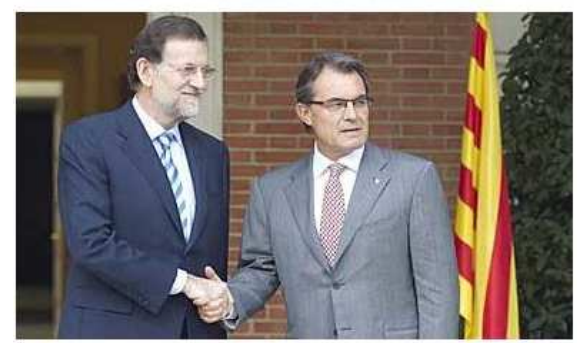

Fotografía 2
ABC. 20-09-2012

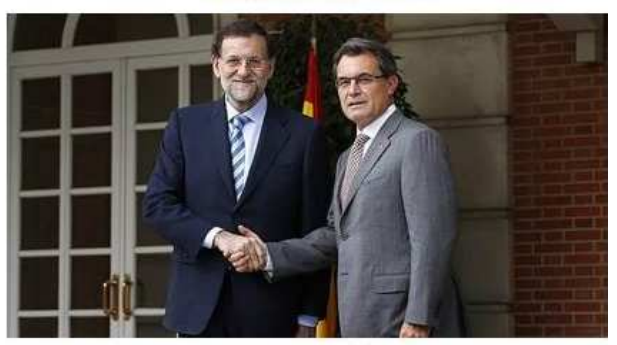

Fotografía 3

Fotografía 1: lavanguardia.com/politica/20140206/54399969617/generalitat-desmiente-

rajoy-mas-reunido.html

Fotografía 2: elmundo.es/elmundo/hemeroteca/2012/09/20/m/

Fotografía 3: abc.es/espana/20130328/abci-encuentros-rajoy-201303271702.html

Consultado el 1-09-2016

Este hecho afectará a la disposición de banderas en la última recepción que se concede al presidente catalán, el 30 de julio de 2014. En la fotografía 8 comprobamos que se incluyen tres banderas a ambos flancos de la puerta principal, a fin de evitar que Artur Mas vuelva a poner en práctica la estrategia empleada en el anterior encuentro (audiencia número quince).

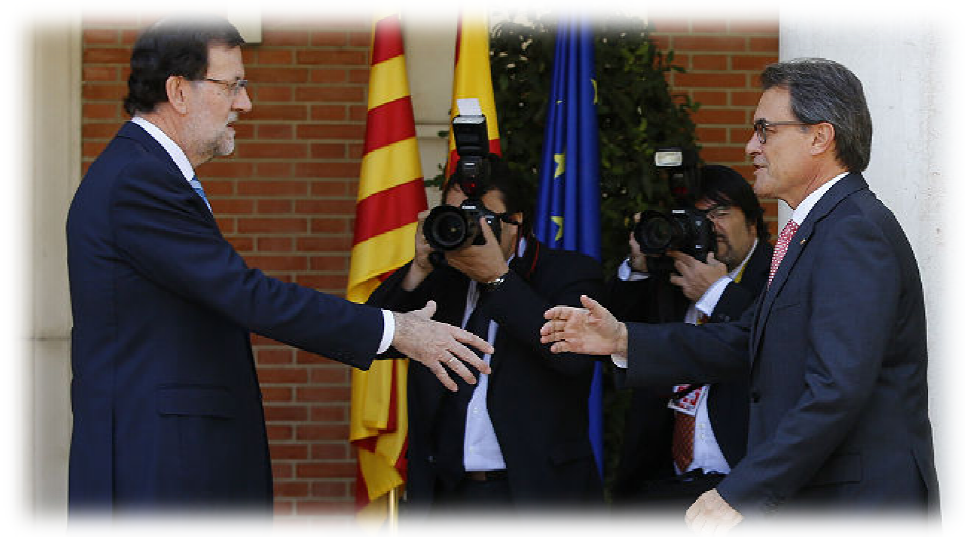

Fotografía 8.

Fuente: vozpopuli.com/actualidad/70482-historia-de-un-desencuentro-constanteentre-artur-mas-y-la-moncloa. Consultado el 1-09-2016 


\subsection{Resultados del análisis de los criterios protocolarios de ordenación espacial y escenografía simbólica}

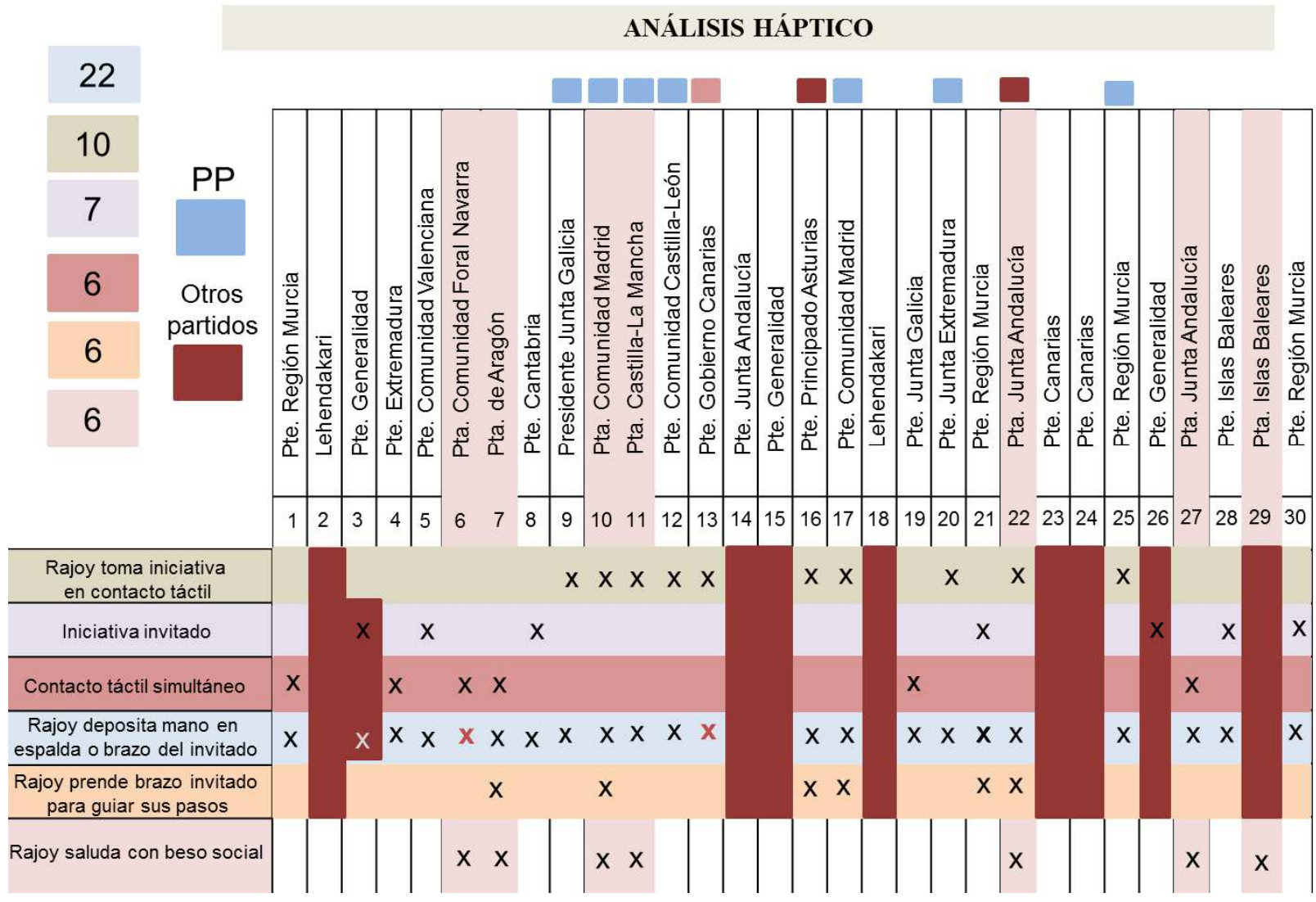

El presidente del Gobierno establece contacto táctil con sus invitados en veintidós ocasiones. En diez de ellas Mariano Rajoy toma la iniciativa a la hora de depositar la mano en la espalda o el brazo de los presidentes de las Comunidades Autónomas. En siete la iniciativa la toma el invitado, y en el resto el contacto es simultáneo. Es de destacar que solo en tres ocasiones en las que el presidente toma esta iniciativa sus interlocutores no pertenecen al partido en el Gobierno.

Consideramos importante mencionar que no hay contacto físico (al margen del momento en que se estrechan las manos) en las visitas que realizan el lehendakari, el presidente catalán, el presidente de Coalición Canaria; tampoco hay contacto táctil con el presidente de la Junta de Andalucía, el socialista José Antonio Griñán; ni con la presidenta de las Islas Baleares, la socialista Francina Armengol.

No se identifican indicadores de poder, dominio y liderazgo en el comportamiento gestual de Mariano Rajoy. Sin embargo, sí se perciben estas señales por parte del presidente de la Generalidad catalana. Lo comprobamos en las figuras 5 y 6 . En su primera entrevista con el presidente del Gobierno, Artur Mas saluda desde la derecha a Mariano Rajoy, lo que permite que el dorso de su mano quede visible ante los medios de comunicación, además coloca la mano izquierda sobre el hombro de su anfitrión. En el segundo encuentro, Mas se 
sitúa junto a la bandera catalana durante el posado ante la prensa, de manera que solo se puede ver esta enseña en las fotografías de la bienvenida ${ }^{9}$. En la tercera recepción, durante la despedida, el presidente catalán usurpa el lugar que corresponde al anfitrión, con la finalidad de transmitir un mensaje de autoridad y dominio frente al representante del Estado español.

\section{Señales de dominio, poder y liderazgo}

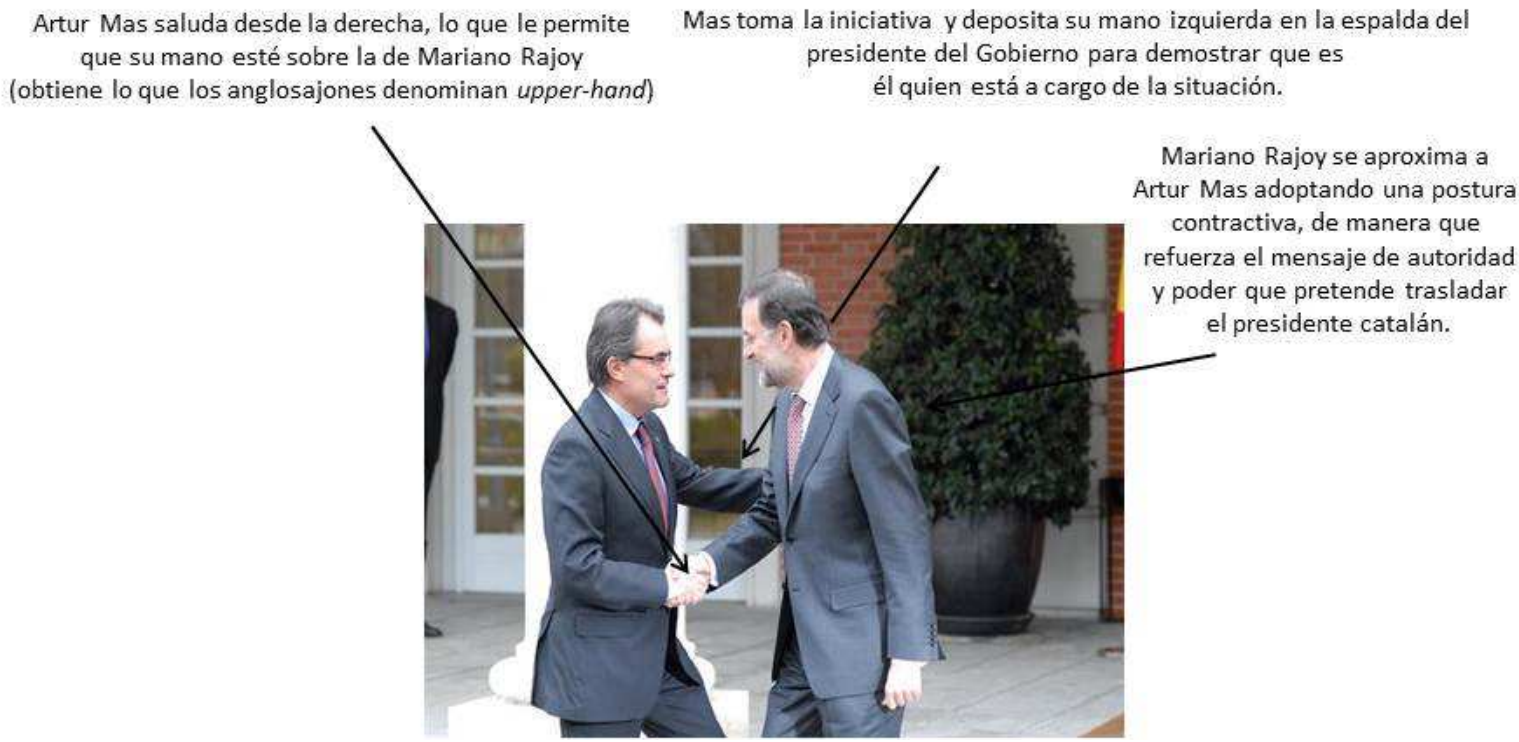

Figura 5. Elaboración propia.

Fuente de la fotografía:

lamoncloa.gob.es/multimedia/galeriasfotograficas/Presidente/Paginas/2012/010212RajoyM as9.aspx

Consultado el 01-09-2016 en Internet

9 Únicamente en la página web de La Moncloa se aprecian las dos banderas, nacional y autonómica, gracias a que el fotógrafo oficial abre el foco para incluir toda la escena. En el resto de medios de comunicación, incluidos los audiovisuales, solo figura la enseña catalana. 


\title{
Señales de dominio, poder y liderazgo
}

\begin{abstract}
Artur Mas se despide del presidente del Gobierno a su salida del Palacio de La Moncloa, para ello se ubica a la derecha de Mariano Rajoy, de esta forma, no sólo se apropia de su lugar, sino que su mano vuelve a quedar por encima de la del presidente de la nación. Por la disposición y actitud de ambos interlocutores se diría que Mas es el anfitrión y Rajoy ejerce de invitado.
\end{abstract}

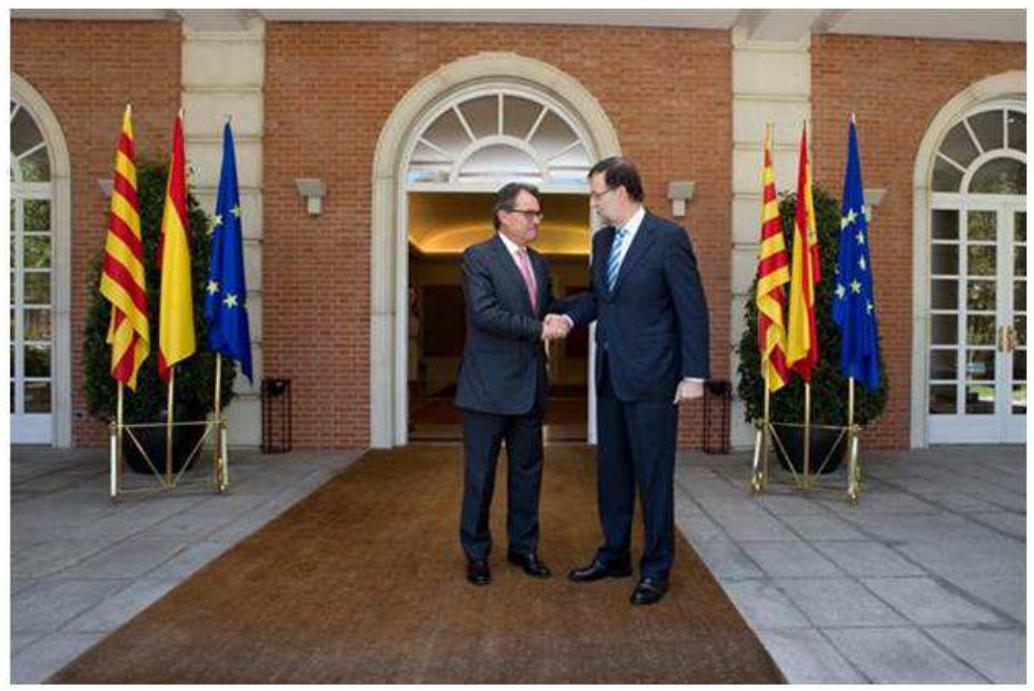

Figura 6. Elaboración propia.

Fuente de la Fotografía:

lamoncloa.gob.es/multimedia/galeriasfotograficas/Presidente/Paginas/2012/010212RajoyM as9.aspx

Consultado el 01-09-2016

\section{DISCUSIÓN}

Del análisis de estas audiencias se infiere que la Presidencia del Gobierno realiza un uso indiscriminado de la jerarquía espacial, sin que hayamos podido percibir ningún objetivo en esta actuación errática. El comportamiento errático de un presidente de Gobierno, o de cualquier otro cargo que ejerce de anfitrión, afecta negativamente a su imagen, pues transmite la ausencia de control, dominio y liderazgo de la situación de la que está a cargo. Los responsables del control de la imagen deberían tener presente que la adjudicación del espacio es fundamental en el ámbito que nos compete pues supone una importante herramienta de comunicación no verbal a la hora de proyectar autoridad.

Se comprueba que la Presidencia del Gobierno de la nación también realiza un uso indiscriminado de la escenografía simbólica. En algunas recepciones se incorpora la bandera de la Unión Europea y en otras se prescinde de ella. Uno de los cambios de pauta vexilológica, en el que se incluyen de nuevo las tres banderas -nacional, autonómica y europea-, parece estar concebido para la tercera audiencia que se concede a Artur Mas, pues esta alteración impide que el presidente de la Generalidad vuelva a posar únicamente 
junto a la enseña catalana. Sin embargo, esta disposición de tres mástiles que el Ejecutivo utiliza en varios de los encuentros no es apropiada para este tipo de acto. Veamos por qué: aunque es cierto que no hay una legislación específica sobre el uso de la bandera europea, la Comisión Europea recomienda incorporarla en un lugar especial en los edificios públicos, fuera de la ordenación de las banderas oficiales, el 25 de marzo, -coincidiendo con el aniversario de la firma del Tratado de Roma-, el 9 de mayo, el Día de Europa y en los actos de carácter europeísta. Aun otorgando libertad a los países miembros sobre su utilización, la Unión Europea les advierte sobre la inconveniencia de su uso excesivo (Fuente, 2004). A nuestro entender este sería un caso de "uso excesivo", pues el que nos ocupa es un acto de ámbito nacional en el que se ven involucrados el Gobierno de la Nación y el Gobierno de una Comunidad Autónoma. No se trata de una fecha conmemorativa de carácter europeísta, ni de un encuentro bilateral entre dos países miembros. Recordemos, además, que la peana con tres banderas que incluye la enseña europea es la empleada por el Ejecutivo para la recepción de jefes de Estado y presidentes de Gobierno de otros países. Por lo tanto, la solución que ofrece el gabinete de Protocolo del Ejecutivo, como respuesta al desafío soberanista del Gobierno catalán, es inadecuada, pues no parece reparar en que este distingo equipara la figura del presidente autonómico a la de un jefe de Estado extranjero, de manera que el resultado favorece los anhelos soberanistas de Artur Mas.

Por otra parte, hemos comprobado que el comportamiento háptico del presidente del Gobierno no puede interpretarse en términos de transmisión de poder o dominio, pues su interacción táctil únicamente persigue reforzar el mensaje de bienvenida. Los gestos que realiza el presidente responden más al grado de cordialidad y complicidad que desea transmitir que a la intención de mostrar señales de territorialidad. De hecho, el comportamiento táctil de Rajoy es profuso e intenso con los presidentes de Consejo de Gobierno que pertenecen al propio partido y claramente escaso cuando sus interlocutores son integrantes de otras formaciones políticas. En consecuencia, su conducta táctil está más relacionada con las simpatías y antipatías que le inspiran sus invitados que con una estrategia comunicativa que tenga como objetivo proyectar algún tipo de mensaje más allá de sus propias filias y fobias. Por el contrario, se identifican numerosos gestos de dominio en el lenguaje corporal de Artur Mas durante su interacción con el presidente del Gobierno. De esta manera, pretende transmitir la idea de autoridad y dominio frente al Estado español.

\section{CONCLUSIONES}

Del análisis de la jerarquía espacial y del uso que se realiza de la simbología concluimos que el protocolo es un instrumento de transmisión y refuerzo del poder, dominio y liderazgo del actor político. Por otra parte, resulta contradictorio que haya sido uno de los invitados, y no la Presidencia del Gobierno, quien haya utilizado los recursos espaciales y simbólicos para afianzar y reforzar los suyos. Este estudio ha demostrado que se obtiene un conocimiento más profundo de las circunstancias que rodean a un acontecimiento público cuando las imágenes se analizan con criterios protocolarios, pues proporcionan información más allá de la puramente denotativa. De este modo, se ha comprobado que el protocolo 
resulta una herramienta clave a la hora de interpretar las imágenes de los políticos que ofrecen los medios de comunicación.

Por otra parte, a través del estudio del contacto táctil (indicadores de poder, dominio y liderazgo), se constata que el concepto de protocolo, asociado a la jerarquía espacial y a la precedencia, resulta insuficiente para controlar con eficacia la presencia visual de un líder político, ya que no contempla elementos fundamentales que influyen directamente en su imagen pública; es decir, la inclusión del análisis háptico ha brindado la posibilidad de confirmar que para proyectar una determinada imagen son decisivos otros factores vinculados al lenguaje corporal del sujeto protagonista.

\section{BIBLIOGRAFÍA Y WEBGRAFÍA}

Cuadrado Esclapez, C. (2000). Protocolo y comunicación en la empresa y los negocios (8 Ed.). Madrid. FC Editorial.

Cuadrado Esclapez, C. y Rodríguez Cuadrado, R. (2015). El ABC en la organización de eventos. Madrid. Fundación Confemetal.

Fuente Lafuente, C. (2010). Protocolo Oficial. Las instituciones españolas del Estado y su ceremonial. Madrid. Ediciones Protocolo.

La Moncloa. Home <http://www.lamoncloa.gob.es/Paginas/index.aspx>

López-Nieto y Mallo, F. (1997). Manual de protocolo (2ª Ed.) Barcelona. Editorial Ariel, S.A.

ABC.es CATALUÑA. Artur Mas planta a la vicepresidenta española en un acto con empresarios. -Consultado el 3 de junio de 2015 <http://www.abc.es/localcataluna/20131017/abci-artur-planta-vicepresidenta-espanola-201310171938.html>

EL COMERCIO.es Así se vive en La Moncloa <http://www.elcomercio.es/noticias/201111/20/Media/M1-1807156471--300x180.JPG>

EL HERALDO MONTAÑÉS. Miguel Ángel Revilla: lo que sea para estar en la poltrona. $<$ https://elheraldomontanes.wordpress.com/2015/07/07/miguel-angel-revilla-lo-que-seapara-estar-en-la-poltrona/>

EL PAÍS, Madrid. Aznar y Maragall constatan sus notorias discrepancias tras reunirse en La Moncloa <http://elpais.com/elpais/2004/01/08/actualidad/1073553422_850215.html>

EL PAÍS, Cataluña. Mas planta a Sáenz de Santamaría y a Fomento por una cuestión de protocolo -Consultado el 6 de abril de 2015 <http://ccaa.elpais.com/ccaa/2013/10/17/catalunya/1382033408_155944.html> 
EL MUNDO, Madrid. Artur Mas se mantiene "decidido" a hacer la consulta y Rajoy le asegura "que no se va celebrar". <http://www.elmundo.es/espana/2014/07/30/53d7e583ca4741ab528b4594.html>

- Consultado el 4-07-2016 en Internet

Fernández, Fernando (2010). La importancia del protocolo en la comunicación política. El Molinillo. Revista de Comunicación Política. № 22, abril. -Consultado el 3 de febrero de 2014 <http://compolitica.com/wp-content/uploads/N\%C3\%BAm.-22-El-Molinillo-de-ACOP-abril2010.pdf>

Revista de Arquitectura. Interiorismo y política. 5 presidentes del Gobierno de España y un mismo despacho. Palacio de La Moncloa, Madrid, España (1977- 2011). $<$ http://es.paperblog.com/interiorismo-y-politica-5-Presidentes-del-gobierno-de-espana-yun-mismo-despacho-palacio-de-la-moncloa-madrid-espana-1977-2011-661454/>

LA VANGUARDIA. Mas rechaza asistir a un acto de Fomento en el que coincidía con Santamaría. -Consultado el 9 de mayo de 2015 <http://www.lavanguardia.com/politica/20131017/54391295330/mas-evita-asistir-actofoment-treball-santamaria-protocolo.html>

Ley 39/81 de 28 de octubre, sobre la Bandera Nacional (BOE 271 de 12 de noviembre) Consultado el 3 de febrero de 2017 en Internet <https://www.boe.es/buscar/act.php?id=BOE-A-1981-26082>

Real Decreto 2099/1983, de 4 de agosto, por el que se aprueba el Ordenamiento General de Precedencias en el Estado. Presidencia del Gobierno "BOE" núm. 188, de 8 de agosto de 1983. Referencia: BOE-A-1983-21534. -Consultado el 3 de febrero de 2017 en Internet <https://www.boe.es/buscar/pdf/1983/BOE-A-1983-21534-consolidado.pdf>

Toledo, César (2017). Háptica, el poder del tacto como canal de comunicación no verbal en la política. -Consultado el 7 de mayo de 2017 <http://www.analisisnoverbal.com/hapticaen-comunicacion-no-verbal-politica/>

VOZPOPULI > ESPAÑA. Historia de un desencuentro constante entre Artur Mas y La Moncloa. $<$ http://vozpopuli.com/actualidad/70482-historia-de-un-desencuentro-constante-entreartur-mas-y-la-moncloa>

WIKIPEDIA. José María Aznar <http://es.wikipedia.org/wiki/Jos\%C3\%A9_Mar\%C3\%ADa_Aznar> 